monitoring of the E.C.G., at least initially, an hourly pulse chart, and frequent E.C.G.s, while the dose is adjusted. The drug should be abandoned if it has insufficient effect to relieve Stoke-Adams attacks or failure, if it gives rise to unpleasant side-effects, or if the rate or rhythm is so unstable as to be intolerably disturbing or dangerous.

\section{Summary}

The usefulness and the limitations of an oral long-acting isoprenaline preparation (Saventrine) in the treatment of heartblock have been assessed from the results of 26 trials on 21 patients since 1962 .

In $46 \%$ of the trials the need for artificial pacemaking was averted or overcome.

It is suggested that this preparation should be tried in every case where artificial pacemaking is to be considered or has failed, except in patients who have shown ventricular tachycardia or ventricular fibrillation.

The need for close observation during the trial stage is stressed and the dosage scheme used is outlined.
Side-effects, which were few in this series, are described. Sudden withdrawal of a large dose must be avoided.

ADDENDUM.-Since this report was completed, experience with Saventrine in a further 10 patients with complete heartblock has not diminished the validity of these findings and conclusions, except that in two cases severe diarrhoea prevented effective use of the drug. It occurred on a dose of $300 \mathrm{mg}$. daily in one case and $450 \mathrm{mg}$. daily in the other.

\section{REFERENCES}

Adelman, F. P., Kravitz, C. H., and Gouley, B. A. (1957). F. A. Einstein med. Cent., 5,196

Bluestone, R., and Harris, A. (1965). Lancet, 1, 1299.
Chandler, D., and Clapper, M. I. (1959). Amer. F. Cardiol., 3, 336. Chandler, D., and Clapper, M. I. (1., Bernstein, H., and Jaffe, H. L. (1962), Irving D. W., Gold, Heart

Dack, S., and Robbin, S. R. (1961). 7. Amer. med. Ass., 176, 505.

Fleming, H. A., and Mirams, J. A. (1963). Lancet, 2, 214.

McGaff, C. J., Cohen, N. K., and Leight, L. (1959). Arch. intern. Med., 104, 242 .

Nathanson, M. H., and Miller, H. (1952). Circulation, 6, 238.

Nathanson, M. H., and Miller, H. (1952). Circulation, 6, 238. (1958). Ibid., 17, 526.

\title{
Renal Failure Associated with Low-molecular-weight Dextran Infusion*
}

\author{
T. O. MORGAN, $\dagger$ M.B., M.R.A.C.P. ; J. M. LITTLE, $\ddagger$ M.B., F.R.A.C.S. ; W. A. EVANS,§ M.B., D.C.P., M.C.P.A.
}

Brit. med.f., 1966, 2, 737-739

Low-molecular-weight dextran has gained a place in medical practice since the early reports of Gelin (1961) and Gelin and Ingleman (1961), and was reviewed by Moore (1963), who maintained that there were three broad indications for its use in surgical practice: (1) trauma with shock, where low tissue blood-flow was responsible for at least part of the ensuing physiological disturbances ; (2) extracorporeal circulation ; and (3) localized ischaemia or the threat of localized ischaemia.

There seems no doubt that low-molecular-weight dextran is a potent rheological agent, capable of improving the flow in small vessels; its usefulness has been reported in Gram-negative septicaemia, vascular grafting, coronary occlusion, and Raynaud's phenomenon. Its antithrombotic properties have been studied and applied clinically by Winfrey et al. (1963).

Its use in the management of ulceration of the skin after arterial occlusion was reported by Bienenstock and Harding (1964). This application of low-molecular-weight dextran has been less closely studied, and may well have more risk because long courses, extending over some days, are involved. The regimen proposed by Bienenstock and Harding was to give a loading dose of $500 \mathrm{ml}$. in two hours and a maintenance dose "by slow continuous intravenous infusion for three days." Thereafter $500 \mathrm{ml}$. was given over six hours every three days until healing occurred.

The renal effects of low-molecular-weight dextran have attracted interest. Acute infusions produce an increase of urine flow in normal individuals. Gelin (1961) maintained that the diuresis was due to improved kidney perfusion. This claim has been questioned by Matheson et al. (1964).

* From the Royal Prince Alfred Hospital, Sydney, New South Wales, and the Department of Pathology, University of Sydney.

+ Clinical Superintendent (Medical).

Flinical Superintendent (Surgical).

$\$$ Lecturer in Pathology.
Eliasson (1963) warned that the use of dextran in dehydrated patients could be dangerous because the dextran concentration in the tubular urine could become so high that the urine was rendered highly viscous. Hint (1963), commenting on a paper by Artz (1963) on the use of low-molecular-weight dextran in burns, warned that this highly viscous urine might actually threaten anuria, and stressed that patients receiving the substance must also be given adequate amounts of fluid. Eliasson, however, asserted that low-molecular-weight dextran had not been shown to cause any functional disturbances of the kidney.

We report three cases of acute renal failure, one of them fatal, following the use of low-molecular-weight dextran in prolonged courses. All three patients were adequately hydrated throughout, and in none of them was there evidence of any severe underlying renal disease. Renal biopsy in all cases showed grossly swollen tubular cells obliterating the tubular lumen. No glomerular, arterial, or interstitial pathology was found. Staining for dextran revealed a gross accumulation of that substance in the tubular cells. There were no intraluminal dextran casts. Because we felt that intermittent dosage was not entirely logical, we chose to use slow continuous infusions of $10 \%$ low-molecular-weight dextran in dextrose, averaging 1,000 ml. each day.

\section{Case 1}

A man aged 77 was admitted to hospital with an acute poplitealartery obstruction. He was well hydrated, his blood-pressure was $270 / 110 \mathrm{~mm} . \mathrm{Hg}$, and the apex beat was in the sixth left intercostal space in the anterior axillary line. Blood urea, serum electrolytes, and microscopical examination of a centrifuged urine were normal. $\mathrm{He}$ was started on continuous intravenous heparin (30,000 units/ day) and low-molecular-weight dextran solution. An infusion of 
$500 \mathrm{ml}$. of $10 \%$ low-molecular-weight dextran in dextrose-water was given in the first hour and a similar amount over the next six hours. The subsequent dosage, the total fluid intake, and the urinary output are indicated in Fig. 1.

Two days after the beginning of treatment he became confused. His leg became gangrenous, requiring amputation on the 14th day. As indicated (Fig. 1), the urine volume decreased and the blood urea rose prior to this surgical procedure. There was no evidence of systemic infection, hypotension, or dehydration in the first 13 days.

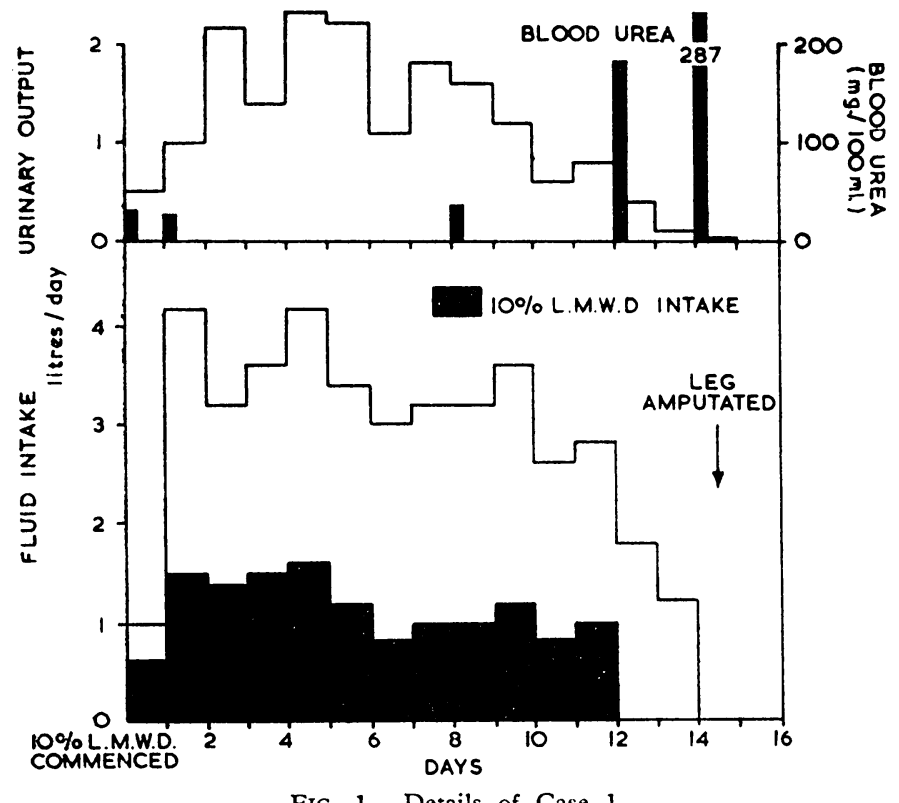

FIG. 1.-Details of Case 1.

At necropsy (Dr. Wong) the heart was hypertrophied and there was atheroma in the large vessels. The renal tubular cells were swollen, leaving slit-like lumina. The cytoplasm of these cells contained material which was P.A.S.-positive. There were hypertensive changes in the arterioles.

\section{Case 2}

A woman aged 67 had a myocardial infarction and was treated with heparin for eight days. Two days later she developed an ischaemic left hand and was given 1 litre of $10 \%$ low-molecularweight dextran in dextrose daily. At this time the blood urea, serum electrolytes, and urine were normal. The fluid intake, urine output, and low-molecular-weight dextran dosage are given in Fig. 2. Four days after beginning therapy the patient became confused. Later she became oliguric and required peritoneal dialysis for six days. A diuresis occurred and the blood urea fell gradually to 31

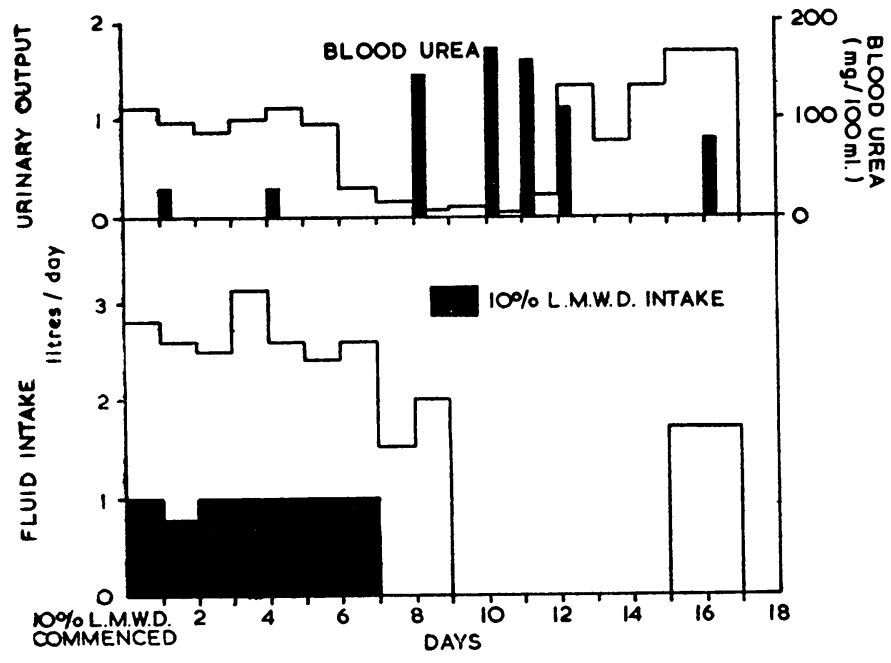

Fig. 2.-Details of Case 2. mg. $/ 100 \mathrm{ml}$. She developed $20-25$ red blood cells and profuse cellular and granular casts in her urine. These disappeared with her recovery.

A renal biopsy performed on the 10th day was divided into two pieces, and one piece was fixed in formol saline and the other in absolute alcohol. Haematoxylin-and-cosin stain showed large vacuolated foam cells in the distal and proximal tubules. The specimen, fixed and processed in a non-aqueous medium, stained strongly with P.A.S. This material appeared to be water-soluble and was not present in the specimen fixed in formol saline.

\section{Case 3}

A woman aged 58 was admitted to hospital for skin-grafting to a radionecrotic ulcer. The cardiovascular and renal systems were normal. Blood urea was $25 \mathrm{mg} . / 100 \mathrm{ml}$. and urine was normal Two days after the skin graft an ischaemic area developed and daily infusions of $1,000 \mathrm{ml}$. of $10 \%$ low-molecular-weight dextran in dextrose was started. Four days later the patient, who had been adequately hydrated, became oliguric. This oliguria continued for three days before a diuresis began. Mannitol, two infusions of $50 \mathrm{~g}$. each, was given within six hours of the oliguria being detected without an increase in the urinary output (Fig. 3).

Renal biopsy performed at this time showed similar changes to those observed in the second case.

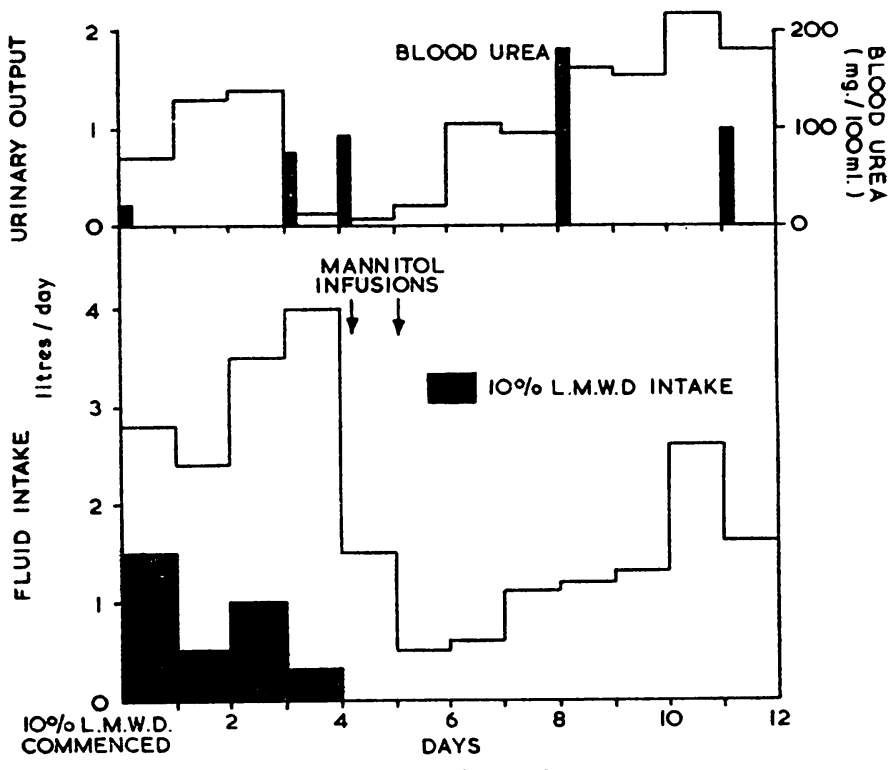

FIG. 3.-Details of Case 3.

\section{Discussion}

The only indication of renal disease in these patients before the infusions was the generalized vascular disease from which two of them were suffering. Manifestations of arterial disease were regarded as indications for therapy. All the patients received liberal fluid allowances in addition to their intravenous dextran. None of them suffered episodes of hypotension during treatment. All had a characteristic renal-biopsy appearance (Fig. 4).

We assume that the anuria is unlikely to be due to tubular blockage by dextran, as suggested by Hint (1963), but to luminal blockage by distended tubular cells, or even to tubularcell failure. The tubular cells can be seen to be crammed with a foamy material, which we assume to be dextran. The tubular lumen is reduced to a slit. A detailed analysis of the histological findings will be reported later (Evans and Wong, 1966).

Low-molecular-weight dextran is being used in great quantities, and its employment as a short-term flow-improver seems established and logical. Its use over longer periods to gain time for collateral development around an arterial block 
is much less certainly established. While dramatic early improvement has been seen many times, the long-term results have been disappointing. We do not think that a definite advantage will be shown over the results that can be obtained with intravenous heparin drips.

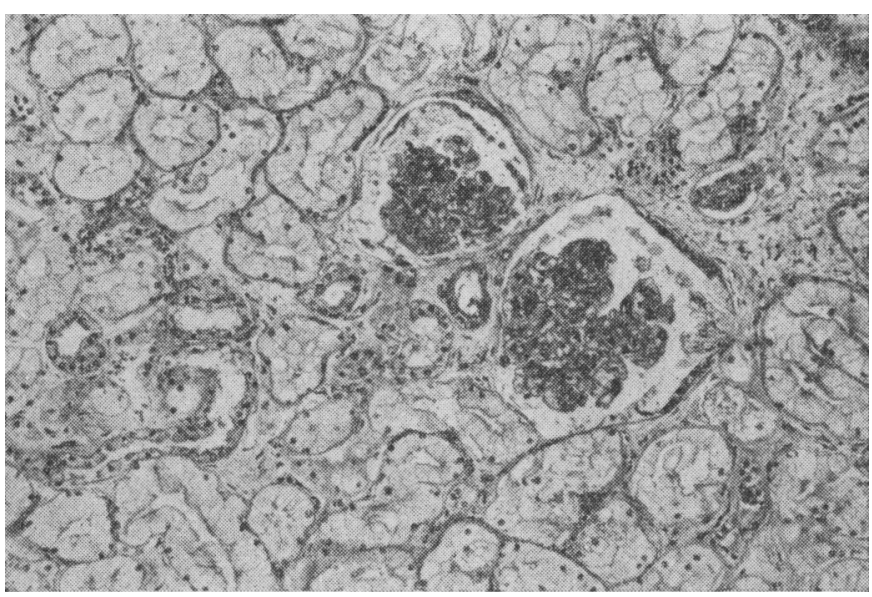

FIG. 4.-Typical renal biopsy appearance. Note distension and vacuolation of renal tubular cells and marked reduction of tubular lumen. (Haematoxylin and eosin. $\times 110$.)

\section{Summary}

Three cases of profound oliguria following courses of lowmolecular-weight dextran are reported. Two patients had generalized vascular disease but no other evidence of renal involvement. All were given adequate fluids during treatment and none suffered episodes of hypotension. Renal biopsy material was obtained from each case, and a florid form of "osmotic nephrosis" was noted in each. There was no evidence that oliguria was due to intraluminal aggregations of dextran; rather it seemed that either luminal compromise by greatly distended tubular cells or cellular impairment by contained dextran was responsible. The value of low-molecularweight dextran in such cases is uncertain, but it is obvious that prolonged courses should be employed with the utmost caution if they are to be used at all.

\section{REFERENCES}

Artz, C. P. (1963). Proceedings of Conference on Evaluation of LowMolecular-Weight Dextran in Shock, p. 107. National Academy of Science, Division of Medical Sciences, National Research Council, U.S.A.

Bienenstock, J., and Harding, E. L. T. (1964). Lancet, 1, 524.

Eliasson, R. (1963). Low Molecular Weight Dextran, p. 4. Symposium held at Royal Society of Medicine, London.

Evans, W. A., and Wong, N. (1966). Aust. N.Z. J. Surg. In publication. Gelin, L. E. (1961). Acta chir. scand, 122, 333.

- and Ingelman, B. (1961). Ibid., 122, 294.

Hint, H. (1963) Proceedings of Conference on Evaluation of LowMolecular-Weight Dextran in Shock, p. 48. National Academy of
Science, Division of Medical Sciences, National Research Council, Science,
U.S.A.

Matheson, N. A., Irvin, T. T., and Hedley, A. J. (1964). Lancet, 2, 501.

Moore, F. D. (1963). Surg. Clin. N. Amer., 43, 577.

Winfrey, E. W., Nabel, C. B., Rhea, C. G., and Foster, J. H. (1963). Proceedings of Conference on Evaluation of Low-Molecular-W eight Dextran in Shock, p. 80 . National Academy of Science, Division of Medical Sciences, National Research Council, U.S.A.
* This paper was presented at a meeting of the Heberden Society in May 1966. Requests for reprints to Mr. Geoffrey F. Walker, Queen Mary's Hospiral for Children, Carshalton, Surrey.

t Institute of Orthopaedics and the Royal National Orthopaedic Hospital, London.
So far as was possible patients were selected who had only one lower limb very severely paralysed, but who walked regularly and who constantly wore one long-leg calliper. Many of these patients also had some paralysis in the stronger leg. This enabled a comparison to be made between the stronger and the weaker leg of the same individual.

As a further control the radiographs of a similar number of unselected people that had been taken during a field survey conducted by the Arthritis and Rheumatism Council in the Leigh Area were examined (Kellgren and Lawrence, 1958). This allowed a comparison to be made between the joints of the weaker and stronger legs, and also between each of these and the radiographic appearances of a random group of control joints.

An attempt was made to assess the degree of weight-bearing activity of each patient, and in all the patients any history of joint symptoms, injuries, or operations was obtained. Examination included an assessment of the muscle-power of the trunk and legs as well as measurements of joint movements. The presence or absence of ligamentous instability was noted.

It was decided to concentrate on the hip- and knee-joints because these have the highest incidence of osteoarthrosis in 